\title{
PACINADOESTUDANTE
}

\section{CARACTERIZAÇÃO DOS SERVIÇOS DE CIRURGIA AMBULATORIAL NO MUNICÍPIO DE RIBEIRÃO PRETO*}

\author{
Fabiana Diniz Pereira** \\ Giovana Abrahão Araújo** \\ Giovanna Terezinha Cândido** \\ Karina Machado Peron** \\ Ligia de Oliveira Pereira** \\ Marilia Marcondes Campoamor** \\ Mônica Telma R.A. da Silva** \\ Rosana Aparecida Spadoti Dantas***
}

\section{INTRODUÇÃO}

A cirurgia ambulatorial começou nesse século, com o primeiro serviço inaugurado em 1961, no Butter Worth Hospital, em Michigan. No ano seguinte houve a abertura de unidade semelhante na Universidade da Califórnia. Porém, o maior estímulo para o seu desenvolvimento foi a instalação do Surgicenter Phoenix, em 1970. Este destinava-se a prestar assistência qualificada aos pacientes, cuja a cirurgia era por demais complexa para o consultório médico sem, no entanto, exigir uma hospitalização. Tal modalidade assistencial viria a ser o protótipo moderno da intervenção cirúrgica, fosse ela realizada em unidades hospitalares ou independentes (JAMES, 1987).

Atualmente, nos EUA, realizam-se por ano, aproximadamente, 20 milhões de intervenções cirúrgicas, sendo que, destas, 40 a $45 \%$ podem ser feitas sem hospitalizar o paciente (JAMES, 1987).

No Brasil, a alta demanda de portadores de afecções cirúrgicas, passíveis de tratamento em ambulatório é uma realidade. A implementação de cirurgias ambulatoriais contribuiu para a redução do uso de leitos hospitalares, deixando-os livres para atendimentos de pacientes que exigem cuidados mais complexos (Tashiro apud SILVA et al., 1997).
O serviço de cirurgia ambulatorial pode ou não estar ligado à uma instituição hospitalar, e se apresentar como serviços: integrados (localizado dentro do hospital); separados (apesar de situar-se nos limites do hospital, é auto-suficiente); de curta permanência (custeados independentemente e operados sem filiação ao hospital); e, prestados no consultório (WATSON \& SANGERMANO, 1997).

Do ponto de vista legal, a prática da cirurgia ambulatorial quando realizada em serviço independente do hospital, está regulamentada pela resolução no 1409/ 94 do Conselho Federal de Medicina (SILVA et al., 1997).

As intervenções em unidades ambulatoriais abrangem as cirurgias de pequeno e médio porte, sob efeito de anestesia local ou regional e de diferentes especialidades, tais como: amigdalectomia, rinosseptoplastia, tenorrafia e miorrafia, correção de fístula arteriovenosa, postectomia, vasectomia, exérese de nódulo de mama, curetagem uterina, hemorroidectomia e fissurectomia, biópsias e remoção da vesícula biliar por minilaparotomia. Cirurgias pediátricas como herniorrafia, postatectomia e ocquidopexia também podem ser realizadas nestas unidades (SILVA et al., 1997).

$\mathrm{Na}$ seleção do paciente a ser submetido à

* Trabalho apresentado na disciplina de Enfermagem Cirúrgica, pelos alunos do $6^{\circ}$ semestre de graduação da Escola de Enfermagem de Ribeirão Preto da Universidade de São Paulo (EERP), sob orientação da Prof ${ }^{a}$ Rosana Aparecida Spadoti Dantas

** Discentes do $6^{\circ}$ semestre de graduação em enfermagem da Escola de Enfermagem de Ribeirão Preto da Universidade de São Paulo

*** Professora Assistente da disciplina de Enfermagem Cirúrgica do Departamento de Enfermagem Geral e Especializada da Escola de Enfermagem de Ribeirão Preto da Universidade de São Paulo 
cirurgia ambulatorial deve-se considerar alguns fatores: idade, condição física e mental, risco anestésico, atitudes em relação à cirurgia ambulatorial, situação social e familiar.

Os candidatos a procedimentos sob anestesia podem ser ordenados pela classificação americana de anestesiologia (American Society of Anesthesiologists - ASA) sendo que, no caso de cirurgia ambulatorial, devem pertencer à classe I (possuírem processo patológico não sistêmico ou ausência de alterações fisiológicas bioquímicas ou psíquicas) ou classe II (distúrbio sistêmico de grau leve) (WATSON; SANGERMANO, 1997).

A cirurgia ambulatorial apresenta as seguintes vantagens: evita ou diminui o risco de infecção hospitalar; colabora na redução da ansiedade pré-operatória, tanto do paciente, como de seus familiares; proporciona retorno mais rápido para o ambiente doméstico e social; e reduz os custos para o paciente e para a instituição. No entanto, o paciente pode não obedecer às instruções pré-operatória, não dispor de um acompanhante e de transporte para ir à unidade, ou mesmo ficar preocupado com a falta de retaguarda caso ocorra complicações no ato anestésico-cirúrgico, sendo estas algumas das desvantagens da cirurgia ambulatorial.

\section{OBJETIVO}

Diante do exposto objetivamos: caracterizar os Centros Cirúrgicos Ambulatoriais de dois hospitais de Ribeirão Preto (SP).

\section{METODOLOGIA}

Foram realizadas visitas aos serviços de cirurgia ambulatorial de dois hospitais de grante porte, ambos localizados em Ribeirão Preto (SP), sendo um da rede pública e outro da rede privada de saúde.

Para caracterizar quanto à estrutras, funcionamento e recursos humanos, optamos por entrevistar uma enfermeira de plantão de cada centro cirúrgico visitado.

Foi utilizado roteiro contendo questões pertinentes ao tempo de existência do serviço, número de salas cirúrgicas, horário de funcionamento, número de procedimentos diariamente realizados, tipos de cirurgias e de anestesia, composição da equipe de enfermagem e funções do enfermeiro.

As entrevistas foram realizadas no mês de novembro de 1997, por alunas de graduação da Escola de Enfermagem de Ribeirão Preto da Universidade de São Paulo, as quais estavam cursando a Disciplina de Enfermagem Cirúrgica.

\section{RESULTADOS}

Para melhor visualização das características levantadas estas foram apresentadas na forma de quadro, designando por Hospital A, o da rede privada, e Hospital B, o da rede pública de saúde.

\begin{tabular}{|c|c|c|}
\hline $\begin{array}{l}\text { CARACTERISTICAS } \\
\text { ABORDADAS }\end{array}$ & HOSPITAL A & HOSPITAL B \\
\hline Ano de Instalação & 1994 & 1997 \\
\hline Horánio de atendimento & 7 às $20 \mathrm{~h}$ & 7 às $19 \mathrm{~h}$ \\
\hline $\begin{array}{l}\mathrm{N}^{\circ} \text { de procedimentos } \\
\text { diários }\end{array}$ & 30 & 10 \\
\hline Tipos de cirurgia & $\begin{array}{l}\text { Todas as } \\
\text { especialidades } \\
\text { cirúrgicas, de } \\
\text { pequeno médio } \\
\text { porte }\end{array}$ & $\begin{array}{l}\text { Todas as } \\
\text { especialidades } \\
\text { (exceto cirurgias } \\
\text { torácicas e } \\
\text { pediátricas) }\end{array}$ \\
\hline Tipos de anestesia & Geral e local & $\begin{array}{l}\text { Local, regional e } \\
\text { b lo que i o s } \\
\text { exceto raqui e } \\
\text { peridural }\end{array}$ \\
\hline Equipe de Enfermagem & $\begin{array}{l}1 \text { enfermeiro } \\
10 \text { auxiliares } \\
2 \text { atendentes }\end{array}$ & $\begin{array}{l}2 \text { enfermeiros } \\
8 \text { auxiliares }\end{array}$ \\
\hline Função do Enfermeiro & $\begin{array}{l}\text { Fredbrimartemente } \\
\text { adrinistrativa }\end{array}$ & $\begin{array}{l}\text { Administrativa } \\
\text { e assistencial }\end{array}$ \\
\hline
\end{tabular}

\section{CONSIDERAÇÕES FINAIS}

Os Centros Cirúrgicos Ambulatoriais visitados na cidade de Ribeirão Preto, encontram-se dentro do que propõem a literatura.

Embora sejam recentes, nota-se uma aceitação e um crescimento acelerado do número de procedimentos realizados. Podemos atribuir este fato às inúmeras vantagens que o serviço de cirurgia ambulatorial apresenta.

Nota-se que os recentes avanços nesta área estão de certa forma ligados às questões financeiras.

\section{REFERÊNCIAS BIBLIOGRÁFICAS}

01. JAMES, E. et al. Grande cirurgia ambulatorial. Clínicas cirúrgicas da América do Norte, v. 4, 1987.

02. SILVA, M.A.A. et al. Enfermagem na unidade de centro cirúrgico. 2. ed. São Paulo: Pedagógica e Universitária, 1997.

03. WATSON, D.S.; SANGERMANO, C.A. Cirurgia ambulatorial. In: MEEKER, M.H.; ROTHROCK, J.C. Cuidados de enfermagem ao paciente cirúrgico. 10. ed. Rio de Janeiro: Guanabara Koogan, 1997. cap. 27, p. 1059-1077. 